\title{
Antibodies to the N-Terminal Domain of Angiotensin-Converting Enzyme (ACE2) That Block Its Interaction with SARS-CoV-2 S Protein
}

\author{
V. G. Krut ${ }^{a}$, I. V. Astrakhantseva $a$, S. A. Chuvpilo ${ }^{a}$, G. A. Efimov ${ }^{b}$, S. G. Ambaryan ${ }^{a}$, \\ M. S. Drutskaya ${ }^{a, c}$, and Academician S. A. Nedospasov ${ }^{a, c, *}$ \\ Received October 10, 2021; revised October 15, 2021; accepted October 15, 2021
}

\begin{abstract}
SARS-CoV-2 is a new coronavirus that is the cause of COVID-19 pandemic. To enter the cell, the virus interacts via its surface $S$ protein with angiotensin-converting enzyme 2 (ACE2), the main entry receptor on the cell membrane. Most of protective antibodies, including those induced by vaccinations, target the $\mathrm{S}$ protein, preventing its interaction with the ACE2 receptor. We have evaluated an alternative strategy for blocking the S-ACE2 interaction using new antipeptide antibodies to the $\mathrm{N}$-terminus of the ACE2 molecule. These antibodies allow detection of human ACE2 in vitro and ex vivo.
\end{abstract}

Keywords: COVID-19, peplomers, peptides, receptor DOI: $10.1134 / \mathrm{S} 160767292201001 \mathrm{X}$

The SARS-CoV-2 virus, a massive infection with which caused a devastating pandemic, the COVID-19 disease, also in Russia [1], uses angiotensin-converting enzyme (ACE2), a membrane-bound protease, as its main receptor on human cells. The peplomers of the virion, formed by the $\mathrm{S}$ protein multimers, come into contact with ACE2 through their receptor-binding domain (RBD). It is believed that neutralizing antibodies in recovered and vaccinated persons bind precisely to these domains on the peplomeres of the virus and prevent its interaction with the ACE2 receptor and the entry of the virus into the cell. In this study, we investigated an alternative way to disrupt the interaction of the virus and the receptor using antibodies to the $\mathrm{N}$-terminal domain of ACE2 of a person involved in contact with RBD.

On the basis on the data of X-ray structural analysis of the RBD-ACE2 complex [2,3], we selected a 32-amino acids (aa) (P1), which consists of the aa residues 9-50 of the ACE2 sequence and has a wellexpressed alpha-helical conformation. In ACE2, this peptide forms several contacts with the spike proteins of the SARS-CoV-2 coronavirus. This peptide was chemically synthesized by the standard solid-phase

\footnotetext{
${ }^{a}$ Sirius University of Science and Technology, Federal Territory Sirius/Sochi, Russia

${ }^{b}$ National Medical Research Center of Hematology, Ministry of Health of the Russian Federation, Moscow, Russia

${ }^{c}$ Engelhardt Institute of Molecular Biology, Russian Academy of Sciences, Moscow, Russia

*e-mail: sergei.nedospasov@gmail.com
}

method and purified by high-performance liquid chromatography, and its sequence was confirmed by mass spectrometry (data not shown). Simultaneously, a variant of the same peptide was prepared, which contained the fluorescent label $(5,6$-carboxyfluorescein (FAM)) at the $\mathrm{N}$-terminus. Then, two rabbits were immunized with the unlabeled 32-aa peptide without conjugation to a carrier protein in complete Freund's adjuvant; the animals received two injections of the peptide with an interval of 21 days. Although the generated antibodies are polyclonal, we assume that they recognize a very small number of closely located linear epitopes on the human ACE2 molecule, which makes their properties, in fact, similar to monospecific antibodies.

Forty days after the start of immunization, antibodies from rabbit blood serum (hereinafter referred to as $\mathrm{aP} 1 \mathrm{Ab}$ ) were purified by chromatography using protein A-conjugated agarose and tested in ELISA with the peptide antigen used for immunization (Fig. la). In addition, they were subjected to Western blotting analysis with a small recombinant $\mathrm{P} 2$ protein corresponding to the N-terminus of ACE2 (amino acid residues 19-101) (Fig. 1b). The 6His-labeled P2 protein was cloned into the pET-22(+) vector, expressed in E. coli strain BL21, and purified according to the standard method using metal affinity chromatography (Fig. 1c).

At this stage, we assessed the aP1Ab antibodies by their ability to detect human ACE2 in HEK293T cells inducibly producing ACE2 in the Cre-dependent system (Fig. 2a), as well as in the tissues of transgenic 
(a)

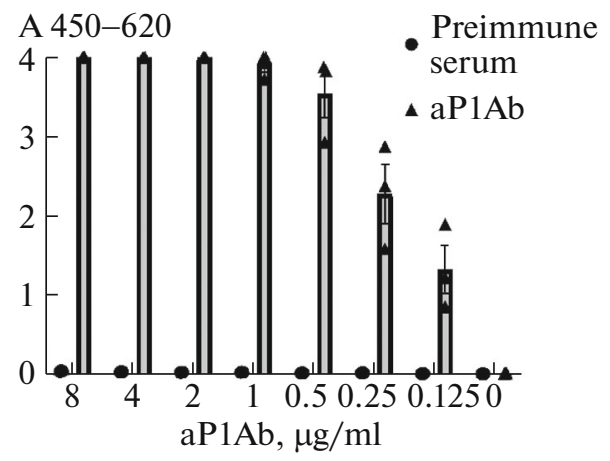

(b)

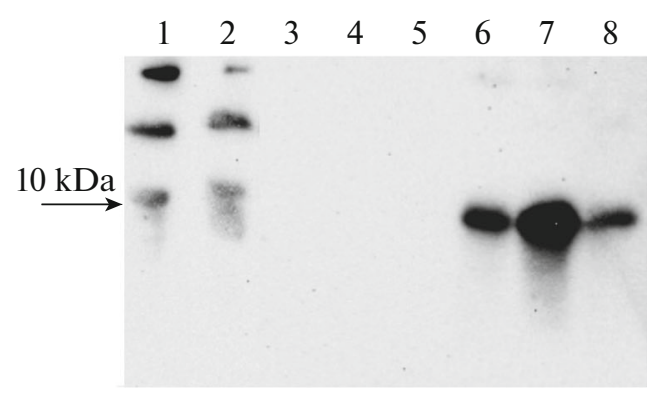

Fig. 1. Interaction of $\mathrm{aP} 1 \mathrm{Ab}$ antibodies with proteins fragments of the N-terminal region of ACE2. (a) Interaction of purified antibodies with $\mathrm{P} 1$ peptide-coated microplate $(1 \mu \mathrm{g} / \mathrm{mL})$ in comparison with preimmune rabbit serum. The reaction was measured after the addition of anti-rabbit antibodies labeled with HRP and TMB (tetramethylbenzidine) substrate (absorbance at 450-620 nm). The experiment was carried out in triplicate, the figure shows the median \pm SEM. (b) Interaction of aP1Ab $(1 \mu \mathrm{g} / \mathrm{mL})$ with purified P2 protein fractions analyzed by Western Blotting. 1-bacterial lysate, 2-flowthrough fraction, 3-5-fractions after washing the column, 6-8-eluate.

(a)

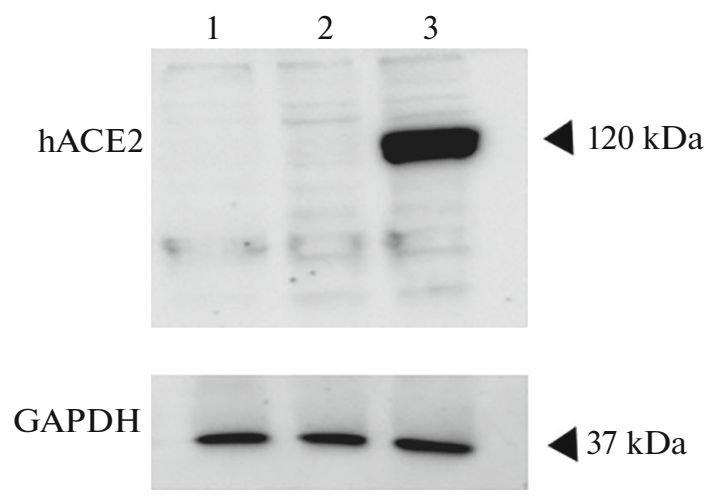

(b)

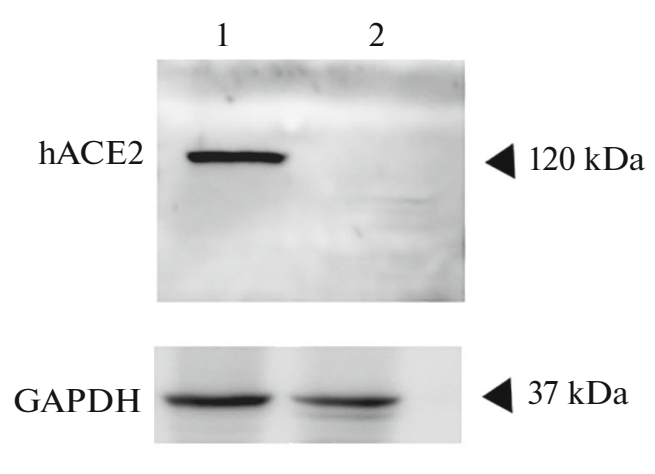

Fig. 2. Evaluation of hACE2 expression in transfected HEK293T cells and in tissues of transgenic mice by Western blotting analysis. (a) 1-HEK293T (without transfection), 2-HEK293T transfected with p-Cre-hACE2-Kat (2.5 $\mu \mathrm{g}), 3-\mathrm{HEK} 293 \mathrm{~T}$ transfected with p-Cre-hACE2-Kat $(2.5 \mu \mathrm{g})+$ plasmid encoding Cre-recombinase $(0.75 \mu \mathrm{g})$. (c) Protein extract isolated from intestinal tissue homogenate: 1-K18-hACE2 transgenic mouse, 2-wild-type C57Bl/6 mouse.

mice expressing human ACE2 under the control of the K18 epithelial promoter (Fig. 2b) [4-7].

It should be noted that the epitopes for $\mathrm{aP} 1 \mathrm{Ab}$ antibodies are located far away from the position of the active center of ACE2 [8] and should not interfere with the enzymatic activity of this protease, which regulates many aspects of the cardiovascular system physiology.

After verification of the purity and specificity of $\mathrm{aP} 1 \mathrm{Ab}$ antibodies, we tested our hypothesis about the possibility of alternative blockade of the interaction between the SARS-CoV-2 S protein and ACE2. The recombinant full-length 6 His-labeled $\mathrm{S}$ protein was expressed in the Expi293F eukaryotic system (Termo) and purified by metal affinity chromatography. S protein adsorbed on the support specifically bound both the 5,6-FAM-labeled P1 peptide (Fig. 3a) and the P2 protein (Fig. 3b).

The addition of $\mathrm{aP} 1 \mathrm{Ab}$ antibodies to the system led to a dose-dependent blockade of the interaction between the $\mathrm{S}$ protein of SARS-CoV-2 and the P2 protein (Fig. 4) corresponding to the ACE2 N-terminus, which is consistent with our hypothesis.

What is the possible clinical significance of our findings? First, in the majority of the existing (tested and approved) prophylactic vaccines, the original Wuhan variant of the S protein of the SARS-CoV-2 virus represent the immunogen. Immune (antibody) response to the RBD of the $\mathrm{S}$ protein of the virus, induced by vaccination, may be ineffective against new variants of the virus [9], which are still able to effectively bind to ACE2. Indeed, the structure of 

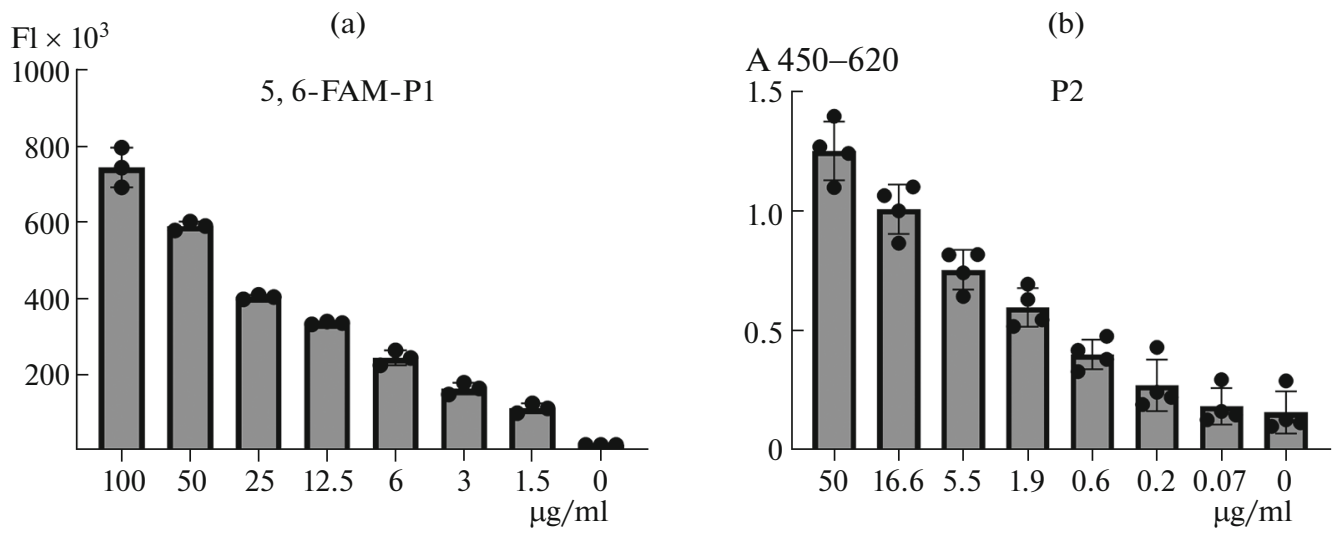

Fig. 3. Interaction of ACE2 fragments with the S protein of the SARS-CoV-2 virus. (a) Fluorescence intensity (FI: excitation$483 \mathrm{~nm}$, emission-530nm) was measured after incubation of peptide 5,6-FAM-P1 for $1 \mathrm{~h}$ at room temperature on a microplate coated with S protein $(1 \mu \mathrm{g} / \mathrm{mL})$. (b) Absorbance (A 450-620) was measured after P2 protein at various incubation concentrations on the microplate coated with S protein. aP1Ab were used as primary antibodies $(1 \mu \mathrm{g} / \mathrm{mL})$. The reaction was measured after the addition of anti-rabbit antibodies labeled with HRP followed by TMB substrate. All experiments were performed in triplicate, the figure shows the median \pm SEM.

ACE2, which is a receptor for all variants of the SARS$\mathrm{CoV}-2$ virus, remains unchanged; therefore, the antibodies to the moiety of the ACE2 molecule that interacts with the RBD of the $\mathrm{S}$ protein of the virion can block any variants of the virus (Fig. 5). It should be noted that a virus that lost its ability to bind to human ACE2 as a result of mutations also loses the ability to enter the cell using this receptor.

Second, autoantibodies to ACE2 in humans have been described in the literature [10]; however, the location of the recognized epitopes on the ACE2 mol-

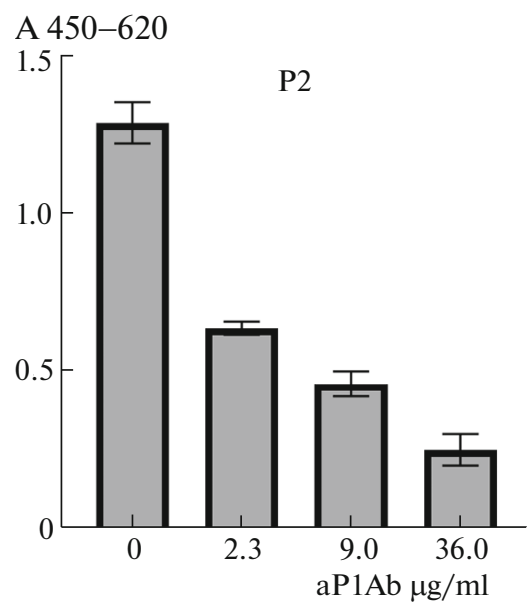

Fig. 4. Dose-dependent blockade of the interaction of ACE2 fragment with S protein of SARS-CoV-2 virus. P2 protein $(200 \mathrm{ng} / \mathrm{mL})$ was preincubated with aP1Ab at various concentrations at room temperature for $30 \mathrm{~min}$. Then, the $\mathrm{P} 2-\mathrm{aP} 1 \mathrm{Ab}$ complex was added to a microplate coated with S protein $(1 \mu \mathrm{g} / \mathrm{mL})$. Absorbance (A 450-620) was measured after incubation with anti-His-HRP antibodies and the addition of TMB substrate. All experiments were performed in triplicate, the figure shows the median \pm SEM. ecule has not been determined. On the basis of our results, it can be assumed that some individuals with autoantibodies to their own ACE2 may have an increased resistance to infection with a wide range of

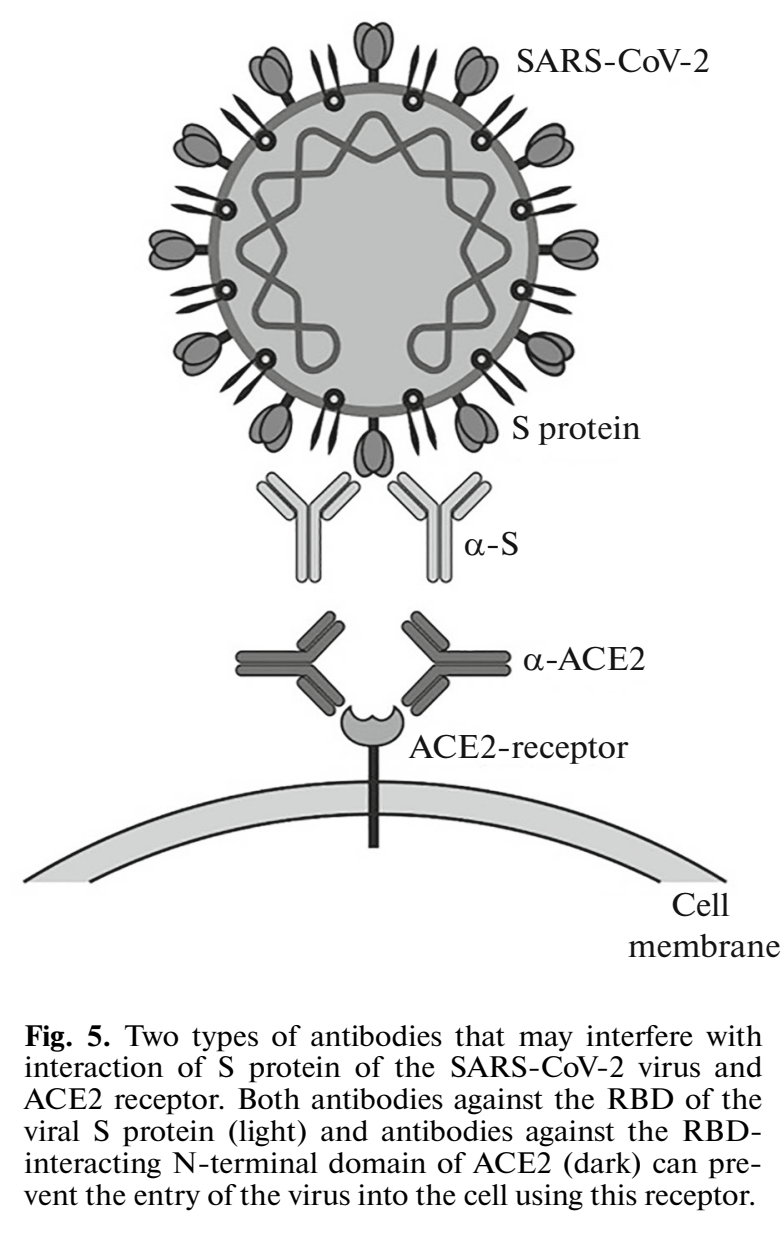


SARS-CoV-2 variants (Fig. 5). This interesting hypothesis can be experimentally tested in the future.

\section{ACKNOWLEDGMENTS}

We are grateful to R. Abagyan and A. Kruglov for advice and discussions, N. Pozdnyakova and V. Gogoleva for help with immunization, A.V. Filatov for providing reagents, M. Nosenko, M. Zhmak, A. Shumeev, and R. Zvartsev for assistance. The study was performed using the equipment of the resource centers "Cell Biology and Immunology" and "Biotechnological Products," Sirius University of Science and Technology.

\section{FUNDING}

The study was supported by the Sirius University of Science and Technology (project IMB-RND-2103) and by the Russian Foundation for Basic Research (project no. 20-0460338).

\section{COMPLIANCE WITH ETHICAL STANDARDS}

The authors declare that they have no conflicts of interest. This article does not contain any studies involving animals or human participants performed by any of the authors.

\section{AUTHOR CONTRIBUTIONS}

V. G. Krut, I. V. Astrakhantseva, and S. A. Chuvpilo have equally contributed to this article.

\section{REFERENCES}

1. Bobik, T.V., Kostin, N.N., Skryabin, G.A., et al., COVID-19 in Russia: clinical and immunological fea- tures of the first-wave patients, Acta Nat., 2021, vol. 13, no. 1, pp. 102-115.

2. Shang, J., Ye, G., Shi, K., et al., Structural basis of receptor recognition by SARS-CoV-2, Nature, 2020, vol. 581, pp. 221-224.

3. Yan, R., Zhang, Y., Li, Y., et al., Structural basis for the recognition of SARS-CoV-2 by full-length human ACE2, Science, 2020, vol. 367, pp. 1444-1448.

4. Zheng, J., Wong, L.R., Li, K., et al., COVID-19 treatments and pathogenesis including anosmia in K18-hACE2 mice, Nature, 2021, vol. 589, pp. 603-607.

5. Yinda, C.K., Port, J.R., Bushmaker, T., et al., K18-hACE2 mice develop respiratory disease resembling severe COVID-19, PLoS Pathog., 2021, vol. 17, no. 1. e1009195.

6. Liu, X., Zaid, A., Freitas, J.R., et al., Infectious clones produce SARS-CoV-2 that causes severe pulmonary disease in infected K18-human ACE2 mice, mBio, 2021, vol. 12 , no. 2 , pp. 1-10.

7. Oladunni, F.S., Park, J.G., Pino, P.A., et al., Lethality of SARS-CoV-2 infection in K18 human angiotensinconverting enzyme 2 transgenic mice, Nat. Commun., 2020, vol. 11, pp. 6122-6139.

8. Turner, A.J., Tipnis, S.R., Guy, J.L., et al., ACEH/ACE2 is a novel mammalian metallocarboxypeptidase and a homologue of angiotensin-converting enzyme insensitive to ACE inhibitors, Can. J. Physiol. Pharmacol., 2002, vol. 80, pp. 346-353.

9. Chen, R.E., Zhang, X., Case, J.B., et al., Resistance of SARS-CoV-2 variants to neutralization by monoclonal and serum-derived polyclonal antibodies, Nat. Med., 2021, vol. 27, pp. 717-726.

10. Takahashi, Y., Haga, S., Ishizaka, Y., et al., Autoantibodies to angiotensin-converting enzyme 2 in patients with connective tissue diseases, Arthritis Res. Ther., 2010, vol. 12, no. 3, pp. 1-8.

Translated by M. Batrukova 